\title{
A VIOLÊNCIA DE GÊNERO NO JORNALISMO DE CELEBRIDADE: UMA ANÁLISE DO CASO KESHA VS. DR. LUKE
}

\author{
Pedro Henrique Lobato Defensor ${ }^{1}$ \\ Ivanise Hilbig de Andrade ${ }^{2}$
}

\begin{abstract}
RESUMO
0 caso Kesha vs. Dr. Luke repercutiu nos portais de notícia de todo o mundo, principalmente nos veículos de jornalismo de celebridade, entre 2014 e 2016. Durante esse período, matérias também estamparam o nome da cantora norteamericana nas manchetes com temáticas como a forma física e vestimentas. A partir do caso, este trabalho realiza uma análise sobre a influência da midiatização na produção de conteúdo dos portais Ego, OK! Magazine e Us Weekly e como isso afeta na seleção e discussão de temas importantes para a sociedade.
\end{abstract}

Palavras-chave: Jornalismo de Celebridades; Análise de Discurso; Violência; Caso Kesha.

\section{ABSTRACT}

The Kesha Vs. Dr. Luke case reverberated in news portals around the world, especially in celebrity journalism vehicles, between 2014 and 2016. During this time, other stories also starred the American singer's name in headlines with themes such as fitness and fashion. For this reason, this analysis discusses the influence of mediatization in the content production of the portals Ego, OK! Magazine and Us Weekly and how it affects the selection and discussion of important topics to all the society.

Keywords: Celebrity Journalism; Discourse Analysis; Violence; Kesha Case.

\section{INTRODUÇÃo}

O jornalismo de celebridade é o principal segmento de informações sobre a vida dos famosos. Nele, os leitores buscam e comentam sobre as preferências e rotinas do seu artista favorito, fazendo qualquer situação transformar-se em potencial para uma grande repercussão. 0 relato de uma cirurgia plástica em alguma figura pública, por exemplo, pode ter o mesmo impacto social de discussão que um caso de violência de gênero dentro do ramo artístico.

\footnotetext{
${ }^{1}$ Graduando em Comunicação Social - habilitação em Jornalismo na Universidade Federal de Uberlândia (UFU). 0 artigo é parte da monografia apresentada, em 2017, como Trabalho de Conclusão de Curso. E-mail: plobatodefensor@hotmail.com

Doutora em Comunicação e Cultura Contemporâneas (UFBA) e docente do curso de Jornalismo e do Programa de PósGraduação em Tecnologias, Comunicação e Educação (PPGCE) da Universidade Federal de Uberlândia (UFU). E-mail: ivaniseha@ufu.br
} 
A visibilidade das figuras públicas intensificou-se com a maior circulação de conteúdo e acessibilidade proporcionados pelo avanço da Internet. Além disso, a instantaneidade possibilita que a produção de notícias seja imediata, provocando aumento de consumo desse tipo de conteúdo.

Em outubro de 2014, a cantora norte-americana Kesha foi destaque nas manchetes de sites e revistas ao iniciar um processo contra seu produtor musical Dr. Luke, alegando que, durante dez anos, o produtor teria "abusado sexual, física, verbal e psicologicamente dela, a ponto de quase perder a vida" para "manter total controle". Em contrapartida, Luke entrou com uma ação contra Kesha, sua mãe e seus representantes por difamação e quebra de contrato ${ }^{3}$.

Todavia, outros acontecimentos também fizeram com que a artista tivesse seu nome estampado nas manchetes dos sites de celebridades no decorrer das investigações e julgamento do caso. Muitas dessas matérias relacionavam-se à vestimenta e a forma física da Kesha, em outras os leitores eram interpelados e instigados a opinar sobre as imagens da cantora. Alguns portais norte-americanos e brasileiros que publicaram esse tipo de conteúdo foram os sites Us Weekly, OK! Magazine e Ego.

Neste contexto, esta pesquisa buscou analisar como os portais de jornalismo de celebridade constroem discursos de violência de gênero, mesmo quando as matérias dizem respeito apenas aos aspectos físicos e da vida privada da celebridade. A partir de enunciados jornalísticos produzidos sobre o caso Kesha vs. Dr. Luke pelos sites Ego, Us Weekly e OK! Magazine, intentou-se mostrar que existe uma construção discursiva machista acerca da imagem da mulher e sua inserção na sociedade nas notícias de celebridades. 0 estudo utiliza base teórica-metodológica da Análise de Discurso de Escola francesa (AD), especialmente sobre o funcionamento do dispositivo de enunciação ${ }^{4}$ operado pelos meios de comunicação.

Inicialmente, apresenta-se uma contextualização sobre os estudos sobre violência de gênero na mídia, em seguida, é realizada uma revisão bibliográfica sobre o jornalismo de celebridade em um contexto de midiatização, para, por fim, apresentar a metodologia empregada e os resultados das análises.

\footnotetext{
${ }^{3}$ Entenda o caso Kesha x Dr. Luke. Disponível em https://goo.gl/LHQ6cR. Acessado em 24/11/2017

${ }^{4}$ A abordagem desses portais está diretamente relacionada com os dispositivos de enunciação utilizados para a construção de sentidos, conceituados por Eliseo Verón (2004). Fausto Neto (2007) afirma que "o conceito de enunciação é definido não pela complexidade intrínseca ao funcionamento da matéria significante, mas pela noção de intencionalidade, aspecto sobre o qual repousaria a completude" (FAUSTO NETO, 2007, p.79). 0 conceito explica como o discurso é produzindo tendo como norte à imagem de quem ou a quem se fala.
} 


\section{VIOLÊNCIA DE GÊNERO E MIDIATIZAÇÃO}

Para Nogueira e Porto Jr. (2016), violência de gênero é um tema abordado de maneira excessiva pelos meios, dando destaque a situações de violência que atingem principalmente a propriedade privada dos indivíduos. 0 caso analisado neste trabalho mostra justamente a violência sofrida pela cantora pelo seu produtor, acusando-o de abuso sexual, físico e mental, levando o assunto à agenda midiática.

Moreno (2012) explica que grande parte da população toma conhecimento da violência principalmente por intermédio dos meios de comunicação. Assim, ela ressalta a importância de se refletir sobre o tratamento que é dado às informações veiculadas e que se enquadram nesse tema.

A violência de gênero está incluída na seleção de noticiabilidade relatada na obra de Ramos e Paiva (2007). De acordo com a Organização das Nações Unidas, no Brasil, a taxa de feminicídios é de 4,8 para 100 mil mulheres - a quinta maior no mundo, segundo dados da Organização Mundial da Saúde (OMS) ${ }^{5}$, calculados em 2016. Porém, Nogueira e Porto Jr. (2016) mostram que as matérias sobre violência contra mulher, mesmo sendo uma pauta recorrente e atraente para os veículos de comunicação, deixam a desejar na qualidade do que é noticiado, no que se refere à abrangência de conteúdo e ao aprofundamento investigativo. Ou seja, é preciso "refletir sobre algumas questões para avançar rumo a uma cobertura midiática sobre a violência contra a mulher que respeite, em critérios investigativos e éticos, a complexidade desse problema que afeta toda sociedade" (NOGUEIRA; PORTO, 2016, p.170).

Cabe discutir, assim, de que maneira os meios de comunicação operam essa produção discursiva da violência de gênero no atual contexto de midiatização e da consolidação do chamado jornalismo de celebridade. Com isso, é possível analisar a abordagem que os materiais produzidos sobre o julgamento da cantora Kesha com o produtor Dr. Luke e também as matérias referentes a cantora, publicadas no período de tempo do caso.

Por midiatização, compreende-se o "processo de dupla face no qual a mídia se transformou em uma instituição semi-independente na sociedade à qual outras instituições têm que se adaptar" (HJARVARD, 2012, p.1), ou seja, de acordo com o autor, a mídia é introduzida no cotidiano de instituições (ex. família, trabalho e religião) a partir da utilização dos meios de comunicação (de massa e de interação) para a realização das suas funções. 
É possível analisar este efeito da midiatização no jornalismo de celebridade, em que os meios de comunicação especializados nesta área tomam e passam para seu público como realidade os ocorridos da vida privada. Esse processo é realizado por uma abordagem totalmente característica, que mistura uma linguagem casual com um discurso construído para causar emoção no leitor. De outro modo, este tipo de jornalismo passou pelo processo de hipermediação, transitando o conteúdo publicado em cópias físicas para o campo online, tendo que adequar o tipo de linguagem, para aumentar a efetividade da comunicação nos tecidos sociais.

Maria Aparecida Pinto (2016) aponta que o jornalismo de infotenimento deve cobrir "estilo de vida, celebridade, esporte, viagem, artes, gastronomia, carro, moda, beleza, filme, tevê, livro, teatro, ou seja, tudo aquilo que estiver ligado ao consumo" (COYLE, p. 41, 1998 apud PINTO, 2016, p. 65), que é o consumo como forma de ostentar a posição social e os benefícios que são advindos.

0 jornalismo de celebridades, segundo Pinto (2016), não tem como foco principal abordar temas com peso social, mas, ao relatar algo que se encaixa neste perfil, já contribui para o agendamento e a discussão do assunto. Contudo, esta área seria uma parte rejeitada, por não ser considerada como séria ou de importância, como diz Morales (1999). 0 caráter sensacionalista desse tipo de produto midiático banaliza seu espaço no âmbito jornalístico.

São características como essas descritas pela autora que servem de base para a análise realizada. A partir da metodologia de análise de discurso, buscou-se verificar como as matérias selecionadas sobre a cantora Kesha, que foram publicadas no período do julgamento contra o produtor Dr. Luke, utilizam de operações de produções completamente influenciados pela midiatização, resultando em matérias e manchetes sensacionalistas que reproduzem e constroem discursivamente a violência de gênero.

\section{ANÁLISE DE DISCURSO COMO METODOLOGIA}

Com a metodologia de Análise de Discursos de linha francesa (AD), em autores como Eliseo Verón (2004), Dominique Maingueneau (2002) e Antonio Fausto Neto (2007), busco-se compreender, a partir do estudo das regularidades e diferenças entre os discursos, como os portais de jornalismo de celebridade retratam assuntos que envolvem diretamente casos de violência de gênero, visto que, esses mesmos sites também publicam notícias com conteúdos que remetem à objetificação da mulher.

Para Dominique Mainguenau (2002, p.50-57), é chamado de discurso os enunciados formais ou pejorativos, ou podem designar qualquer uso restrito da 
língua, desde que possua algumas características essenciais: o discurso é uma organização situada além da frase; ele é orientado; atua como uma forma de ação; funciona como interação; é contextualizado; é assumido por um sujeito; é regido por normas e, por último, o discurso é considerado o centro de um interdiscurso.

A ordem do enunciado é a ordem do que é dito, que está em par com o conceito de enunciação, que se refere ao modo de dizer, ou seja, a diferença está na relação do locutor ao que ele diz, as modalidades do seu dizer, segundo Verón (2004). Em outras palavras, o enunciado é o produto, a materialização do ato de enunciar, a enunciação.

Em um discurso, o autor diz que as modalidades do dizer constroem o dispositivo de enunciação, estratégia bastante utilizada pelos veículos de mídia. Este conceito remete ao enunciador que direciona o seu discurso ao destinatário, no qual o enunciador constrói seu discurso, definindo igualmente a quem ele irá se dirigir. Essa relação estabelecida entre enunciador e destinatário é denominado, segundo Véron (2004), como dispositivos de enunciação.

Interessa saber que o jornalismo se classifica como um discurso que é "dialógico; [...] ao mesmo tempo efeito e produtor de sentidos" e é "elaborado segundo condições de produção e rotinas particulares" (BENETTI, 2007, p.107). Ou seja, a sua compreensão está de acordo com o enquadramento social e ideológico, ou seja, para analisar o discurso é preciso considerar o contexto de produção de sentidos. A fala do sujeito é afetada pelo sistema (língua, cultura, ideologia e imaginário) em que o indivíduo está inserido. A análise do discurso atenta ao movimento (interpretação e fala) da instauração de sentido.

Portanto, a AD revelou-se como método adequado para compreender a construção do discurso e enunciados pelos portais online: OK! Magazine, Us Weekly e Ego, nas matérias publicadas sobre a cantora Kesha entre 2014 e 2016.

Dentro do universo dos portais selecionados definiu-se uma amostra de notícias relacionadas ao tema em análise. Para isso, critérios de seleção, baseados em fundamentos teóricos do jornalismo de celebridade e análise de discurso, foram aplicados dentro desse universo para eleger o material adequado. Assim, foram selecionadas três notícias de cada um dos três portais online em estudo (Ego, OK! Magazine e Us Weekly) totalizando nove matérias. A quantidade de textos que compõem o corpus serve para identificar com precisão as regularidades dos pontos que remetem à violência de gênero em cada veículo de comunicação, como sugere Benetti (2007). Das três notícias de cada portal, uma é referente ao julgamento Kesha vs. Dr. Luke, como forma de mostrar o contraponto entre os conteúdos destes veículos. 


\section{ANÁLISE}

Estabelecido o conceito de jornalismo de celebridade apresentado por Pinto (2016), que define que esta área deve cobrir o estilo e acontecimentos da vida de uma celebridade e que não tem como foco principal abordar temas com maior relevância social, toma-se o corpus como uma abordagem dos acontecimentos de vida da cantora Kesha que já era pauta por se enquadrar nos conceitos de uma celebridade, e que teve sua imagem reforçada nos portais quando ela processou seu empresário por abuso e violência.

Em janeiro de 2015, os portais Us Weekly, OK! Magazine e Ego publicaram uma matéria sobre a presença da cantora Kesha em uma praia no Brasil. 0 destaque de todas as notícias analisadas era o maiô que ela estava usando. Os sites utilizaram pelo menos duas fotos para ilustrar a notícia, uma manchete que se referia ao maiô e o corpo textual descrevendo a cena.

$\mathrm{Na}$ análise das três manchetes é possível identificar a principal regularidade discursiva entre os sites analisados. Os portais de notícia buscam trazer adjetivos para a construção do seu discurso, de uma forma que irá direcionar a interpretação do leitor para o sentido que a notícia está passando: a ideia de que a Kesha está saudável. Palavras como "slim", "healthy figure", "comportado", trabalham como palavras chaves na construção de sentido deste laudo nas manchetes.

Mas apesar de se tratar do mesmo acontecimento, os portais Ego e OK! Magazine se diferenciam do modo de dizer do portal Us Weekly. Por um lado, existem duas manchetes que apresentam uma enunciação que utiliza de adjetivos mas não deixa o sentido da manchete claro, fazendo com que o leitor precise analisar as imagens anexadas para ter uma interpretação mais precisa; do outro lado temos a manchete com um modo de dizer mais direto, limitando as margens de interpretação do sentido da notícia.

Mesmo com as regularidades e diferenças, as enunciações (de texto e foto) constroem o discurso para intrigar o leitor a buscar imagens para ter uma visão mais precisa sobre a informação que foi passada nas manchetes. Este recurso é comum no jornalismo de celebridade, como afirma Pinto (2016), pois a construção do visual aumenta a curiosidade do público.

Entende-se que manchete, foto e texto das matérias estão diretamente ligados para que o leitor tenha a interpretação que o veículo deseja. Contudo os portais OK! Magazine e Ego utilizaram de pouco recurso textual para construir a notícia, já o portal Us Weekly possui o corpo de texto maior, pois abrange o assunto noticiado, dando abertura para entrevista que representa metade do conteúdo. 
Entre regularidades e diferenças, todos os portais usam adjetivos que objetificam a mulher. Ao julgar o maiô comportado e o físico da cantora, os meios utilizam de fatos (ex. distúrbio alimentar) nas manchetes e textos apenas para chamar a atenção do leitor, ou seja, o fã da Kesha quer ver como ela está após a saída da reabilitação, porém a formação discursiva está baseada em um laudo de aparências e estereótipos e interpreta que aquilo é estar bem.

Figura 1 - Foto do portal Ego da Kesha

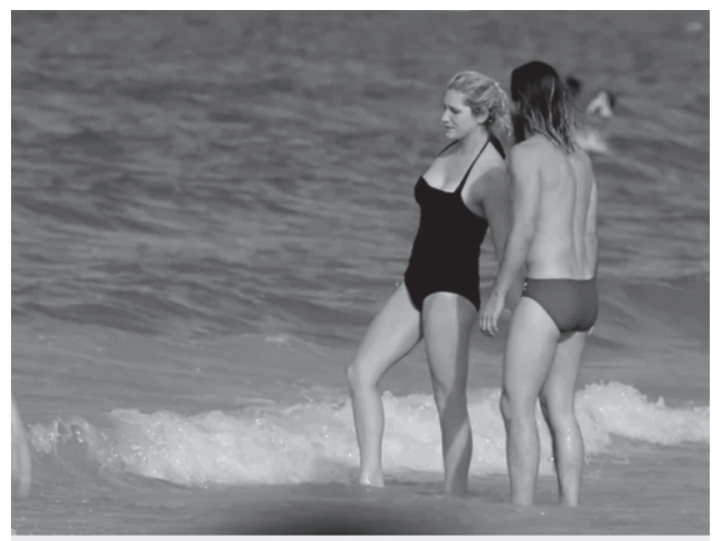

cantora kesha na prala (Foto: GABRIEL REIS)

Fonte: Com maiô comportado, Kesha curte praia com o namorado. Ego, 30 jan. 2015.

Figura 2 - Mosaico do portal OK! Magazine com fotos da Kesha na praia

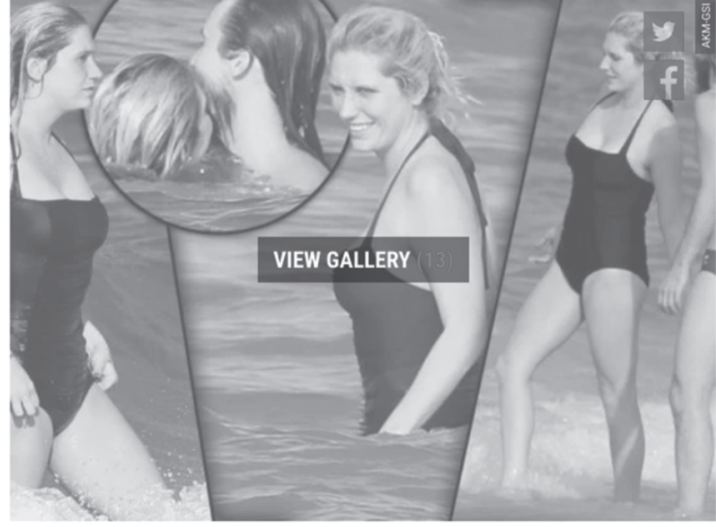

AKM-GSI

Fonte: Kesha Flaunts Healthy Figure In Brazil With Hot Boyfriend After Eating Disorder Rehab. OK! Magazine, 29 jan. 2015. 
Figura 3 - Recorte da foto da Kesha na praia pelo portal Us Weekly.

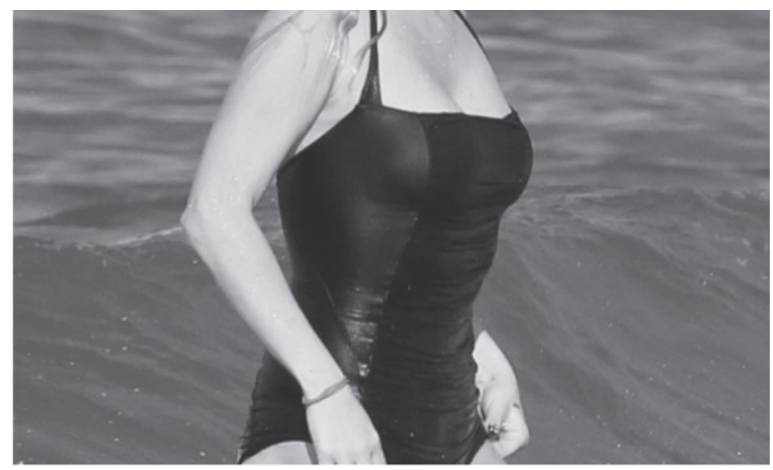

Kesha shows off her fit bod in Brazil AKM-GSI

Fonte: Kesha Displays Fit Swimsuit Bod While Frolicking in Ocean With Boyfriend Brad Ashenfelter — See Her Slim Physique Here. Us Weekly, 29 jan. 2015.

No segundo conjunto de notícias analisado, os dispositivos de enunciação nas manchetes dos portais Us Weekly e OK! Magazine utilizam mais do recurso de suspense nas notícias que focam na aparência estética da Kesha, isto é, fazem referência a possíveis procedimentos estéticos e peças de roupas julgadas pelos portais de notícia como inadequadas. Ao aplicar essas estratégias de comparação e adjetivos sem referentes, o enunciador constrói o discurso da manchete para que quem acesse siga a leitura. Ao fornecer fotos e utilizar o discurso comparativo na manchete, instiga a curiosidade do leitor.

Essas estratégias tornam-se mais frequentes em um contexto de forte midiatização da vida das celebridades. Considerando a evolução da internet, não existe limite de fotos ou texto em uma publicação, ou seja, é viável para o enunciador produzir este tipo de conteúdo que possibilita o uso de galerias com várias fotos. Além da liberdade de conteúdo, a legenda da foto final cria uma ponte entre enunciador e destinatário em que o leitor pode comentar e publicar em tempo real as suas próprias conclusões.

Partindo deste ponto, é possível verificar que o jornalismo de celebridade utiliza desses atributos característicos da midiatização para produzir conteúdo com muita imagem e interação direta, como, por exemplo, no enunciado: "Você acha que ela colocou implantes na bunda? Deixe nos comentários abaixo!". Portanto, é uma regularidade deste tipo de jornalismo o uso exagerado de fotos para "comprovação" do fato. Isto favorece e possibilita a produção de conteúdo que envolva flagrantes em que o leitor faça julgamentos apontando defeitos na vida das celebridades.

Legenda original da última foto da galeria do portal OK! Magazine analisado no segundo conjunto: Did she got butt implants? Let us know on the comments bellow! 
Das matérias analisadas, nenhuma falava do distúrbio e/ou trouxe informações oficiais sobre os distúrbios alimentares da cantora Kesha ou discutiu sobre o assunto, mesmo citando o fato. Todas as fotos foram escolhidas e diagramadas para que o leitor interprete o que está descrito na manchete e/ou no corpo textual. Com isso, é possível afirmar que mesmo com a enunciação e situações diferentes, todas as matérias possuem sentido semelhante voltado para o estereótipo de um corpo ideal, em que segundo esses portais, a cantora não se enquadra.

Os mesmos portais que inseriram adjetivos para se referir aos padrões de beleza de Kesha, que noticiaram informações sobre a forma estética da cantora baseadas em comparativos (sem fontes oficiais), também fizeram a cobertura do julgamento da ação que ela moveu contra seu produtor, Dr. Luke, ou seja, os sites publicaram notícias evidenciando estereótipos sobre a Kesha, mas em outros dias noticiaram a batalha da cantora contra seu produtor que impunha exigências para a mesma se enquadrar nos padrões de beleza inseridos na sociedade. Condições que tiveram consequências, como a internação da artista em uma clínica para se tratar de distúrbios alimentares. Esta observação se relaciona com a afirmação de Pinto (2016), no ponto em que ela afirma que o jornalismo de celebridade não se importa com o impacto ou discussão que um assunto determinado pode gerar, neste caso a discussão sobre violência de gênero, mas sim com a audiência que pode gerar.

Os dispositivos de enunciação tanto dos textos quanto das fotos e vídeos diagramados na página online focaram em vitimizar Kesha de maneiras diferentes. Para noticiar a denúncia da artista, o Ego manteve a objetividade que é uma característica da notícia, de acordo com Erbolato (2008) ${ }^{7}$; o Us Weekly escolheu focar na repercussão gerada da decisão judicial que foi desfavorável para a artista, um lado não explorado por nenhum dos outros portais analisados; o OK! Magazine mantém o uso de adjetivos como estratégia de chamar atenção, além de utilizar os pontos mais chocantes do fato para montar a manchete "Contrato infernal - Mais 6 álbuns com o acusado por estupro", isto é, indica que a cantora está presa ao homem que a teria estuprado, sendo a acusação mais grave feita pela Kesha. Assim, está explícito como a notícia aposta no sensacionalismo para comover o leitor. Isto é uma regularidade em todas as matérias analisadas: o enunciador sabe quem é o seu público.

0 portal Us Weekly foi o único a apresentar um depoimento que mostra a relevância do caso para todas as mulheres. Ao colocar a fala do fã e militante, Michael Eisele, o autor explicita que não importa o que os advogados do acusado alegam, mas que este processo tem representatividade para as mulheres do mundo inteiro, independente se são inspiradas pelo trabalho da Kesha ou não. Além disso, ainda a partir das entrevistas dos manifestantes, o enunciador cobra um posicionamento da gravadora Sony, exigindo a quebra de contrato com o produtor musical. 
Figura 4 - Captura de tela da matéria "Fans Organized a Free Kesha Protest Outside Sony Headquarters"

\section{News Stylish Moms Entertainment Pets Video Give a Gift More - \\ CELEBRITY NEWS \\ Fans Organized a Free Kesha Protes Outside Sony Headquarters}

By Megan French and Evan Real February 26, 2016
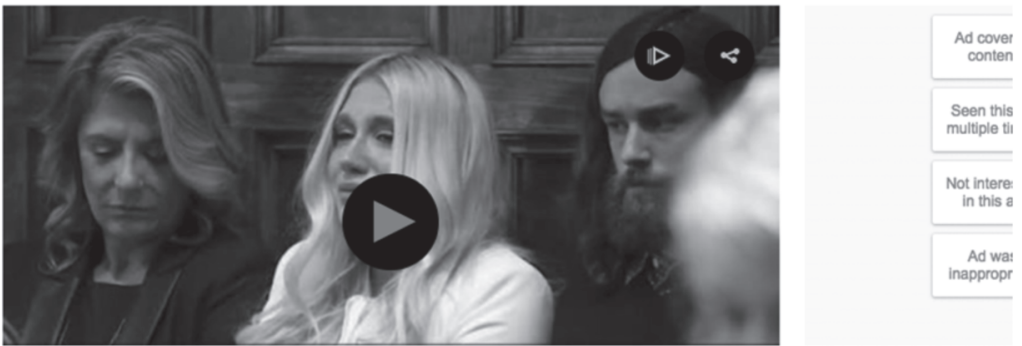

Fonte: Us Weekly, 26 fev. 2016.

Essa matéria é um exemplo de como os portais de jornalismo de celebridade são capazes de cumprir os seus papéis como produtores de conteúdo do infotenimento (estilo de vida, polêmicas e etc) e ainda pautar temas mais densos, como a questão da violência de gênero. Portanto, é possível aferir das análises que o caso de Kesha, como foi construído discursivamente pelos sites de conteúdo sobre celebridades, pode servir de inspiração para que outras mulheres que sofrem violência se manifestem, e as falas apresentadas pelo Us Weekly informou isso ao leitor.

\section{CONSIDERAÇÕES FINAIS}

O caso judicial vivido por Kesha recebeu grande atenção da mídia e foi abordado de diversas maneiras. Durante a análise, foi possível verificar que o Ego utilizou da objetividade como técnica de apresentação da notícia; o site OK! Magazine focou no sensacionalismo, buscando comover o leitor a partir de fotos; e o Us Weekly expôs a repercussão do processo entre os fãs e outras celebridades para atingir 
outros públicos. Portanto, a cantora não foi destaque nas manchetes apenas pela polêmica contra seu produtor. Entre o período do processo (2014-2016), os portais de jornalismo de celebridade também destacaram a figura a artista em matérias com temáticas como estética corporal e padrões de beleza.

As regularidades discursivas identificadas nas matérias se enquadram em estratégias de sensacionalismo para chamar a atenção do leitor. Sabendo que o jornalismo de celebridade nem sempre produz conteúdo para gerar discussões políticas e sociais, os portais noticiam alguns assuntos sem a preocupação com o impacto que podem causar. Todas as matérias que não têm o julgamento como tema principal estão apontando aspectos de padrões de beleza estabelecidos, em que Kesha não se encaixa. Ou seja, os sites reforçam normas estéticas que, neste caso, envolve alguém que estava tratando distúrbios alimentares e acusando alguém por abuso (psicológico e físico).

0 método principal utilizado por esses portais para instigar o seu leitor está no uso dos adjetivos na manchete. Essa tática produz efeito de sentido de objetificação da mulher por julgar uma aparência que não se encaixa nos padrões, que é uma das causas para o desencadeamento de distúrbios alimentares.

Cada vez mais o jornalismo de celebridade investe em conteúdos que trazem grande quantidade de fotos dos artistas e pessoas públicas. Com o aprofundamento dos processos de midiatização acontece também uma mudança na maneira de cobrir o estilo de vida das celebridades, em que os sites podem aumentar sua produção e ilustrar com quantas imagens forem necessárias para convencer o leitor da afirmação da notícia. Outra estratégia recorrente identificada nas análises é o uso da ferramenta dos comentários, que possibilita ao enunciador esconder-se discursivamente atrás da opinião dos leitores, seu coenunciador. Tal ação se processa quando o enunciador convoca o leitor para que ele interaja com a notícia expondo sua opinião sobre o que está sendo apontado, isto é, o destinatário constrói um discurso impondo padrões, bem como o autor faz.

A partir dessa abordagem usada nas matérias analisadas, compreende-se a conclusão feita por Nogueira e Porto Jr. (2016) de que os casos de violência contra mulheres são constituídos com base em pensamentos machistas, que posicionam a mulher em um patamar inferior ao do homem. Isto é localizado principalmente nas imagens selecionadas para ilustrar as matérias, em que a mulher aparece em um momento frágil e vulnerável, enquanto o homem é visto com um sorriso em alguma aparição pública.

0 jornalismo de celebridade é importante para a sociedade, a partir do momento em que casos como este funcionem como oportunidade para estudo e discussão social do assunto. No portal Us Weekly identifica-se um exemplo que pode 
ser seguido por outros portais, quando, na matéria, o enunciador mostrou que a história vivida pela Kesha não é um caso isolado, mas na verdade é algo que muitas mulheres se identificam. Assim, conclui-se que este segmento do jornalismo não precisa perder sua essência em acompanhar o estilo de vida das celebridades, contudo é necessário aplicar um filtro de noticiabilidade e uma metodologia diferente de construção de discurso para conseguir ter credibilidade e exercer sua função com êxito, que é informar e entreter simultaneamente.

Por fim, os sites analisados não problematizam os assuntos que geram grande impacto social. No caso da Kesha, as publicações variam entre matérias sobre o embate judicial da cantora contra o seu produtor referente à violência e outras que constroem e reforçam discursos imponentes de padrão de beleza. Os resultados dessa pesquisa apontam para a necessidade de maior discussão sobre como os meios de comunicação constroem discursos machistas que objetificam a imagem da mulher. Além de buscar compreender qual o sentido de relatar assuntos que discutem os conceitos de violência de gênero, mas também produzir materiais que constroem discursos divergentes.

\section{REFERÊNCIAS}

APARECIDA PINTO, Maria. As personagens do jornalismo de celebridades: Hart e Bob como representações do Jornalismo na animação Os Padrinhos Mágicos. 2016. 239 p. Dissertação (Pós Graduação em Comunicação Social)- Universidade Federal de Minas Gerais, Belo Horizonte, 2016. Disponível em: < https://goo.gl/TDkyLb>. Acesso em: 25 nov. 2017.

\section{BANDEIRA. Lourdes Maria. Violência de gênero: a construção de um campo} teórico de investigação. Sociedade e Estado (UnB. Impresso), v. 29, p. 325- 689, 2014. Disponível em: http://www.scielo.br/scielo.php?script=sci_arttext\& pid=S0102-69922014000200008. Acesso em: 25 nov. 2017.

BENETTI, Márcia. Análise do discurso em jornalismo: estudo de vozes e sentidos. In: LAGO, Cláudia; BENETTI, Márcia (org.). Metodologia de Pesquisa em Jornalismo. Petrópolis: Vozes, 2007, p.107-122.

\section{CASTELO BRANCO, Gabriel. Kesha usa short curtíssimo e deixa bumbum à} mostra. EGO, 6 nov. 2015. Disponível em:

<http://ego.globo.com/famosos/noticia/2015/11/kesha-usa-short-curtissimo-edeixa-bumbum-mostra.html>. Acesso em: 26 nov. 2017. 
COM maiô comportado, Kesha curte praia com o namorado. EGO, 30 jan. 2015. Disponível em: <http://ego.globo.com/famosos/noticia/2015/01/com-maiocomportado-kesha-curte-praia-com-o-namorado.html>. Acesso e m: 26 nov. 2017.

COYLE, J. S. Now, the editor as marketer. In: Columbia Journalism Review, New York, University of Columbia, ano 2, v.37, pp.37-41, jul./ago., 1998.

DID Kesha Get Butt Implants — See Before \& After Photos!. OK! Magazine, 15 jun. 2015. Disponível em: <http://radaronline.com/photos/kesha-butt-implantspics/>. Acesso em: 26 nov. 2017.

ENTENDA o caso Kesha. 0 Globo, 02 ago. 2016. Disponível em: <https://oglobo.globo.com/cultura/musica/entenda-caso-kesha-dr-luke18730532>. Acesso em: 24 nov. 2017.

ERBOLATO, Mário. Técnicas de Codificação em Jornalismo. 5a edição. Petrópolis: Vozes.

FAUSTO NETO, Antônio. Enunciação, auto-referencialidade e incompletude. Revista FAMECOS. Porto Alegre, n.34, p.78-85, dez. 2007.

FRENCH, Megan; REAL, Evan. Fans Organized a Free Kesha Protest Outside Sony Headquarters. Us Weekly, 26 fev. 2016. Disponível em: $<$ https://www.usmagazine.com/celebrity-news/news/fans-organized-a-freekesha-protest-outside-sony-w165463/>. Acesso em: 26 nov. 2017.

HJARVARD, Stig. Midiatização: teorizando a mídia como agente de mudança social e cultural. 2012.

KESHA acusa produtor Dr. Luke de abuso sexual, diz site. EGO, 14 out. 2014. Disponível em: <http://ego.globo.com/famosos/noticia/2014/10/kesha-acusaprodutor-dr-luke-de-abuso-sexual-diz-site.html>. Acesso em: 26 nov. 2017.

KESHA Flaunts Healthy Figure In Brazil With Hot Boyfriend After Eating Disorder Rehab. OK! Magazine, 29 jan. 2015. Disponível em:

<http://radaronline.com/photos/kesha-boyfriend-brazil-vacation-pics/>. Acesso em: 26 nov. 2017.

MAINGUENEAU, Dominique. Discurso, enunciado e texto. Análise de Textos de Comunicação. 2a edição. São Paulo: Cortez Editora, 2002. Cap. 4. p. 51-57.

MARQUINA, Sierra. Kesha Displays Fit Swimsuit Bod While Frolicking in Ocean 
With Boyfriend Brad Ashenfelter - See Her Slim Physique Here. Us Weekly, 29 jan. 2015. Disponível em: <https://www.usmagazine.com/celebritybody/news/kesha-looks-fit-in-swimsuit-with-boyfriend-brad-ashenfelter2015291/>. Acesso em: 25 set. 2017.

MARQUINA, Sierra. Kesha Looks Unrecognizable in Her Latest Instagram Photos. Us Weekly, 19 dez. 2015. Disponível em:

<http://www.usmagazine.com/celebrity-beauty/news/kesha-looksunrecognizable-in-her-latest-instagram-photos-w160040 >. Acesso em: 25 set. 2017.

MORALES, O. E. T. Nos bastidores da telenovela: a produção do noticiário sobre a telenovela "O Rei do Gado" na revista Contigo!. 1999. Tese (doutorado em Ciências da Comunicação). Escola de Comunicação e Artes, Universidade de São Paulo, São Paulo, 1999.

MORENO, Rachel. A imagem da mulher na mídia: controle social comparado. São Paulo: Publischer Brasil, 2012

NOGUEIRA, Rose Dayanne Santana; PORTO JUNIOR, Francisco Gilson Rebouças. Reflexões sobre Gênero, Violência e Mídia. In: Gilson Pôrto Jr.; Ana Carolina Costa dos Anjos (orgs.). DISCURSO MIDIÁTICO: poder, violência e cultura. Porto Alegre: Editora Fi, 2016.

ONU: Taxa de feminicídios no Brasil é quinta maior do mundo; diretrizes nacionais buscam solução. ONUBR Nações Unidas no Brasil, 12 abr. 2016. Disponível em $<$ https://nacoesunidas.org/onu-feminicidio-brasil-quinto-maior-mundodiretrizes-nacionais-buscam-solucao/>. Acesso em: 26 set. 2017.

RAMOS, Silvia; PAIVA, Anabela. Mídia e violência: novas tendências na cobertura de criminalidade e segurança no Brasil. Rio de Janeiro, Iuperj, 2007.

VERÓN, Eliseo. Quando ler é fazer: a enunciação no discurso da imprensa escrita. In: VERÓN, Eliseo. Fragmentos de um Tecido. São Leopoldo: Unisinos, 2004. Cap. 8. p. $215-238$.

VIEIRA, Gabriela. OMS calcula que 35\% das mulheres já sofreram violência. Estadão, 21 jun. 2013. Disponível em: <http://www.estadao.com.br/noticias/geral,oms-calcula-que-35-das-mulheres-jasofreram-violencia,1045282>. Acesso em: 25 nov. 2017. 
6 More Albums With Alleged Rapist - Inside Kesha's Allegations Against Dr. Luke. OK! Magazine, 20 fev. 2016. Disponível em:

$<$ http://radaronline.com/photos/kesha-rape-case-dr-luke-judge-forces-singerwork-attacker/>. Acesso em: 26 nov. 2017. 